\title{
Assessment of Icephobic Coatings-How Can We Monitor Performance Durability?
}

\author{
Nadine Rehfeld *, Björn Speckmann, Claus Schreiner and Volkmar Stenzel \\ Department Paint Technology, Fraunhofer Institute for Manufacturing Technology and Advanced Materials \\ IFAM, 28359 Bremen, Germany; bjoern.speckmann@ifam.fraunhofer.de (B.S.); \\ claus.schreiner@ifam.fraunhofer.de (C.S.); volkmar.stenzel@ifam.fraunhofer.de (V.S.) \\ * Correspondence: Nadine.Rehfeld@ifam.fraunhofer.de
}

Citation: Rehfeld, N.; Speckmann, B.; Schreiner, C.; Stenzel, V. Assessment of Icephobic Coatings-How Can We Monitor Performance Durability?. Coatings 2021, 11, 614. https:// doi.org/10.3390/coatings11060614

Academic Editor: Jianying He

Received: 26 February 2021

Accepted: 18 May 2021

Published: 21 May 2021

Publisher's Note: MDPI stays neutral with regard to jurisdictional claims in published maps and institutional affiliations.

Copyright: (c) 2021 by the authors. Licensee MDPI, Basel, Switzerland. This article is an open access article distributed under the terms and conditions of the Creative Commons Attribution (CC BY) license (https:// creativecommons.org/licenses/by/ $4.0 /)$.

\begin{abstract}
Significant progress in the field of icephobic coatings has raised a demand for evaluation criteria to assess and monitor the related icephobic effects and their durability. The initial coating performance in preventing ice formation and reducing ice adhesion needs to be proven over a given period by withstanding technically relevant stressors. In this study, silanized polyurethane (PUR) coatings are assessed in conjunction with a standardized accelerated ultraviolet (UV)-ageing procedure in order to identify potential monitoring tools that are also applicable during in-service inspections. Wettability and roughness parameters are recorded after pre-defined ageing intervals, compared with the ice adhesion strength, and tested using a modified centrifuge. Correlation assessments indicate that the chosen parameters cannot generally be used for the monitoring of icephobic effects for the selected material class. It is more likely that specific coating parameter sets need to be defined for in-service monitoring, as an important step towards the integration of icephobic coatings into technical applications.
\end{abstract}

Keywords: icephobic coating; silanized PUR; durability; UV-ageing; ice adhesion; centrifuge test; correlations; monitoring; wettability; surface roughness

\section{Introduction}

Icephobic coatings are of great interest for applications in various fields, such as aviation, wind energy, and the automotive industry. At present, however, unsolved technical challenges prevent their use in many sectors. In general, icephobic coatings can be defined as materials that hinder ice from forming on surfaces and/or reduce the adhesion of ice to surfaces. Their benefits have been widely discussed [1-6]. For aircraft applications, the current approaches mainly aim at combining active ice protection systems (IPS) with icephobic coatings in hybrid IPS to significantly reduce the required heating energy [7,8], improve mechanical deicing measures [9], or to solely use the coatings for rotating parts [10]. However, the upcoming challenges for their integration into IPS are manifold. Table 1 summarizes the relevant topics, with no claim to completeness.

The list of challenges appears tremendous and might be the reason for the lack of "final results", despite the high number of developmental projects that have been conducted over the past decade, both within Europe and beyond. One of the main problems is that projects could address, in many cases, only a certain few of the various challenges; furthermore, the inherent complexity has prevented the completion of their developments and integration into technical applications.

This paper delivers the results of an industry-driven durability study for icephobic coatings, including the assessment of the wettability and roughness surface properties as potential monitoring parameters for icephobic effects. UV radiation is one of the main stressors for exterior coatings and was therefore selected for a standardized ageing scenario. The assessment of icephobic effects is conducted by measuring ice adhesion strength with the help of a modified centrifuge. Degradation in the context of this study 
is linked to the change in surface properties and ice adhesion strength during the ageing process. Test results are used to study correlations between surface properties and icephobic performance, as a first step in the definition of evaluation criteria. In the context of the challenge types defined in Table 1, this study contributes to "materials", but also delivers results for "tests" and "requirements". Our results will help to define follow-up studies for the most promising materials covering the change in surface chemical composition and morphology during ageing processes, as well as the influence of film thickness and elastic modulus (not addressed in this paper). Deep understanding of relationships between material formulation and degradation is essential to further improve the materials and to identify appropriate evaluation criteria. This contributes towards the integration of icephobic materials into various technical applications.

Table 1. Challenges associated with the use of icephobic materials for technical applications.

\begin{tabular}{cl}
\hline Type of Challenge & \multicolumn{1}{c}{ Main Identified Topics } \\
\hline Material & $\begin{array}{l}\text { Resistivity against, e.g., erosion stress, abrasion, radiation, and chemical fluids, } \\
\text { without loss of performance [11-14]. }\end{array}$ \\
\hline Ice-Testing & $\begin{array}{l}\text { Complex ice formation/removal processes to be adopted in (lab-)test designs } \\
\text { with high reproducibility. Significance of tests to be proven [15,16]. }\end{array}$ \\
\hline Standardization & $\begin{array}{l}\text { A vast range of independently developed test systems need to be harmonized } \\
\text { based on improved understanding about application relevance [17-19]. }\end{array}$ \\
\hline Requirements & $\begin{array}{l}\text { Definition requires fundamental understanding of needs for icephobic } \\
\text { material performance and relevant test specifications [20]. }\end{array}$ \\
\hline Integration, Certification & $\begin{array}{l}\text { Interactions with existing IPS/current operational modes and monitoring } \\
\text { tools to be defined based on the results of previous research [9,21,22]. }\end{array}$ \\
\hline
\end{tabular}

\section{Materials and Methods}

Silanized polyisocyanate-curing acrylic resins were used (see Figure 1) for this study. This material selection was based on the expected icephobic properties and their high relevance to the desired application (exterior parts). According to Kreder at al. (2016), low ice adhesion values can be achieved with such hydrophobic (e.g., silicone-based) materials $(>10 \mathrm{kPa})$. Even lower values can be considered for slippery liquid-infused porous surfaces (SLIPS) $(>0.3 \mathrm{kPa})[4,23]$. However, the technical robustness and durability of the selected silanized PUR material is thought to be higher. Additionally, chemistry and application techniques are closer to the current state-of-the-art of external coatings, resulting in lower implementation efforts in the case of success. Resins with different grades of silane content and crosslinking densities were selected, as follows:

- "PUR A": highest Si concentration, moderate crosslinking density;

- "PUR B": moderate Si concentration, moderate crosslinking density;

- "PUR C25": moderate Si concentration, increased crosslinking density; and

- "PUR C50": lowest Si concentration, highest crosslinking density.<smiles>[R]OC(=O)C(CC(C)(C)C(CC(C)(C)C)C(=O)OCCO)C(C)(C)CC(C(=O)O[Ge])C(C)C(C)C</smiles>

Figure 1. General chemical structural formula of the used silanized PUR coatings. 
The formulations were kept at a "basic level", in order to allow for studies on direct correlations between coating compositions and test results. This should provide an improved understanding of the development needs for long-lasting icephobic materials.

All values in Table 2 give the mass percentage on total. Typically, the resin components are dissolved in PUR grade solvents in solid contents of 50-75\%.

Table 2. Typical silanized PUR formulations used in this study.

\begin{tabular}{cc}
\hline Components & Mass (\%) \\
\hline Silanized polyacrylate polyol & $50-67.5$ \\
Polyacrylate or polyester polyol & $0-12.5$ \\
Solvent of different volatility & 10 \\
UV-stabilizers/HALS & 2 \\
Surface-active components & 0.5 \\
Organotin catalyst & 0.01 \\
Aliphatic isocyanate (trimer) & 25 \\
\hline
\end{tabular}

The four coating modifications were applied on relevant test coupons by conventional spray application (SATA Jet 90, Ø $1.3 \mathrm{~mm}$; pressure 1.6 Bar; distance $40 \mathrm{~cm}$, temperature $21^{\circ} \mathrm{C}$, relative humidity $40 \%$ ) and cured for $1 \mathrm{~h}$ at $80^{\circ} \mathrm{C}$. The resulting dry coating film thickness was $15 \mu \mathrm{m}$ (acc. to DIN EN ISO 2808:2019 with byko-test $8500 \mathrm{P} \mathrm{Fe} / \mathrm{NFe}$, Byk Gardner, Geretsried, Germany) [24]. Tests started 14 days after coating application, at the earliest. Repeated application trials assured the reproducibility of the production processes.

UV ageing of the coatings was performed using UVTest ${ }^{\circledR}$ (Atlas Material Testing Technology $\mathrm{GmbH}$, Linsengericht, Germany). Test samples were exposed to UV light for a maximum of $1000 \mathrm{~h}$, following the standard DIN EN ISO 16474-3 [25]: method $4\left(0.7 \mathrm{~W} / \mathrm{m}^{2}\right.$ UV(B)-313), which included cycles of UV exposure at $60 \pm 2{ }^{\circ} \mathrm{C}$ and water condensation phases at $50 \pm 2{ }^{\circ} \mathrm{C}$. Surface properties and ice adhesion strength were assessed prior to and after $200 \mathrm{~h}, 500 \mathrm{~h}$, and $1000 \mathrm{~h}$ exposure.

Evaluation methods for the surface characterization included wettability and roughness tests. Wettability tests were performed with a Drop Shape Analyzer DSA 100 (Krüss GmbH, Hamburg, Germany), according to relevant specifications (DIN EN ISO 19403-2,-7) [26]. Surface free energy was determined by measuring the dynamic contact angle of three liquids: water, diiodomethane and ethylene glycol (droplet application $0.2 \mu \mathrm{L} / \mathrm{s}$, total volume $6.0 \mu \mathrm{L}$ ) and calculated according to the method of Owens, Wendt, Rabel, and Kaelble (OWRK). Water sliding angle was determined with a water droplet volume of $20 \mu \mathrm{L}$ and tilting speed of $60^{\circ} / \mathrm{min}$. Sliding angle was defined as the angle at which the advancing and receding angles of the water droplet moved at least $1 \mathrm{~mm}$ from the starting point. Contact angle hysteresis was determined at this sliding angle or at the maximum tilting angle of $90^{\circ}$ (in the case where the water droplet did not run-off) by calculating the difference between advancing and receding angles. Tilting method was chosen as it delivers consistent results for fresh and aged coating surfaces. Roughness data $R_{a}$ (arithmetic average value of roughness profile) and $\mathrm{R}_{\mathrm{z}}$ (maximum height of the profile) were determined using a Perthometer M2 (Mahr GmbH, Göttingen, Germany).

For the evaluation of icephobic performance, an ice adhesion test using a custommade centrifuge was selected. Ice adhesion reduction is an important function of icephobic coatings as ice may form but, upon reaching a critical mass, it should be able to be easily removed from the surface. There are no available standards for this type of test, and many different methods have been developed to assess the ice adhesion reduction in icephobic coatings $[12,15,16,27,28]$. The centrifuge test uses centripetal forces to shear ice from the test surface. Fraunhofer IFAM uses a centrifuge with a modified rotor to place and fasten the prepared beam with the ice in the device [14]. Opposite the ice is a counterweight that can be adjusted, according to the ice mass, to reduce vibrations (see Figure 2a). The centrifuge runs in an ice lab that was cooled to $-8{ }^{\circ} \mathrm{C}$ during the tests (Figure $2 \mathrm{~b}$ ). 


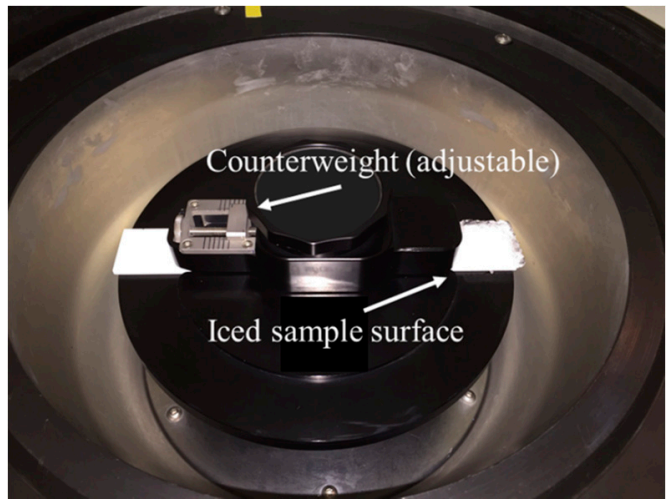

(a)

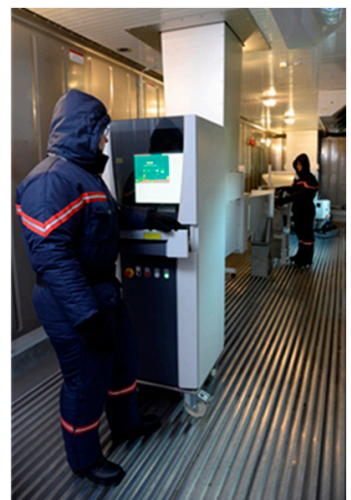

(b)

Figure 2. (a) View inside the centrifuge with modified rotor and prepared sample; (b) ice lab (with ice wind-tunnel) to perform the tests.

Coating surfaces were cleaned prior to the test using isopropanol and a soft Kim wipe tissue. For the tests, impact ice was produced by the insertion of coated test substrates into the test section of the ice wind-tunnel to collect ice, which was formed from supercooled droplets. The conditions for ice formation were temperature $-8{ }^{\circ} \mathrm{C}$, wind speed $95 \mathrm{~m} / \mathrm{s}$, liquid water content (LWC) $0.6 \mathrm{~g} / \mathrm{m}^{3}$, and median volume diameter (MVD) $15 \mu \mathrm{m}$. After $60 \mathrm{~s}$, an ice mass of 3-4 g formed. Next, the prepared sample was fixed in the centrifuge, in which the iced sample was spun at a constantly increasing rate until the ice was sheared off. Separation was detected by a piezoelectric cell when the ice hit the centrifuge wall and was correlated to the rotational speed of the centrifuge rotor. This speed (angular velocity $\omega$ in $\mathrm{rad} / \mathrm{s}$ ) was used to calculate the shear strength of ice to the substrate, according to the following equation:

$$
\tau=\frac{F}{A}=\frac{m_{i c e} \omega^{2} r}{A}
$$

where $m_{i c e}$ is mass of ice $(\mathrm{kg}), r$ is the radius of the rotating beam at the mid-length ice position (m), and $A$ is the surface area of the adherent interface $\left(\mathrm{m}^{2}\right)$ [29]. The calculated values in this study express the adhesive strength of the ice. Note that the calculation of the ice adhesion values assumes a uniform stress distribution at the interface, which is not the case for such test types, as previously discussed in the literature (see, e.g., [15,16]). To account for such a non-uniform stress distribution, results are often expressed in a comparative manner; for example, using the Adhesion Reduction Factor (ARF) as introduced by the AMIL (Anti-icing Materials International Laboratory, Canada) [29]. The ARF is equivalent to the adhesion strength of a baseline material divided by the adhesion strength of ice to the substrate of interest. However, in this study, the ice adhesion strength of fresh and UV-aged coatings was directly compared, considering that the non-uniform stress distribution accounted for all test samples in the same manner. The introduction of an ARF would not further improve the quality of data, in this case.

\section{Results}

The test results of this study present the change in surface properties due to ageing processes caused by UV exposure after 200 h, 500 h, and $1000 \mathrm{~h}$. Surface properties were compared with the results of ice adhesion tests, in order to assess their influence on the icephobic performance. The identified correlations may, then, be used for the definition of assessment rules and advanced test campaigns, in order to pave the way for an improved understanding of the performance durability and monitoring tools for icephobic coatings.

\subsection{Change in Surface Properties Due to UV(B)-Ageing}

The assessed surface parameters included wettability and roughness, as these properties have been widely discussed as the most relevant characteristics for icephobic per- 
formance. For in-service monitoring purposes, these parameters can be assessed using conventional, simple-to-use devices.

\subsubsection{Wettability}

Wettability data included surface free energy (SFE), water contact angle (WCA), water sliding angle (WSA), and contact angle hysteresis (CAH). Results for the coatings used in this study are summarized in Table 3.

Table 3. Wettability of surfaces - initial and after UV(B) ageing-with surface free energy (SFE), water contact angle (WCA), water sliding angle (WSA), and contact angle hysteresis (CAH). Mean of threefold measurement on a minimum of two test samples \pm standard deviations.

\begin{tabular}{|c|c|c|c|c|}
\hline \multirow{2}{*}{$\mathrm{SFE}(\mathrm{mN} / \mathrm{m})$} & \multirow{2}{*}{ Fresh } & \multicolumn{3}{|c|}{ UV(B) Ageing } \\
\hline & & $200 \mathrm{~h}$ & $500 \mathrm{~h}$ & $1000 \mathrm{~h}$ \\
\hline PUR A & $18.77( \pm 0.49)$ & $20.19( \pm 0.19)$ & $22.22( \pm 1.88)$ & $28.81( \pm 1.59)$ \\
\hline PUR B & $20.36( \pm 0.95)$ & $21.36( \pm 0.59)$ & $22.01( \pm 0.91)$ & $31.12( \pm 0.74)$ \\
\hline PUR C25 & $20.94( \pm 0.68)$ & $21.18( \pm 0.96)$ & $22.21( \pm 0.68)$ & $31.83( \pm 1.65)$ \\
\hline PUR C50 & $22.40( \pm 1.18)$ & $23.06( \pm 1.82)$ & $23.06( \pm 1.44)$ & $33.37( \pm 1.57)$ \\
\hline \multicolumn{5}{|l|}{$\operatorname{WCA}\left({ }^{\circ}\right)$} \\
\hline PUR A & $106( \pm 1.3)$ & $106( \pm 0.8)$ & $100( \pm 4.3)$ & $87( \pm 5.3)$ \\
\hline PUR B & $106( \pm 1.7)$ & $104( \pm 0.9)$ & $101( \pm 2.5)$ & $86( \pm 0.8)$ \\
\hline PUR C25 & $106( \pm 0.8)$ & $104( \pm 2.4)$ & $103( \pm 1.1)$ & $87( \pm 3.5)$ \\
\hline PUR C50 & $102( \pm 1.9)$ & $102( \pm 1.0)$ & $102( \pm 0.8)$ & $81( \pm 2.8)$ \\
\hline \multicolumn{5}{|l|}{ WSA $\left({ }^{\circ}\right)$} \\
\hline PUR A & $27( \pm 2.1)$ & $47( \pm 2.6)$ & $62( \pm 4.5)$ & $>90^{1}$ \\
\hline PUR B & $26( \pm 2.8)$ & $59( \pm 4.1)$ & $79( \pm 7.6)$ & $>90^{1}$ \\
\hline PUR C25 & $47( \pm 3.8)$ & $52( \pm 4.4)$ & $75( \pm 8.5)$ & $>90^{1}$ \\
\hline PUR C50 & $56( \pm 4.7)$ & $57( \pm 7.6)$ & $79( \pm 7.7)$ & $63( \pm 7.8)$ \\
\hline \multicolumn{5}{|l|}{$\mathrm{CAH}\left({ }^{\circ}\right)$} \\
\hline PUR A & $19( \pm 2.7)$ & $29( \pm 1.9)$ & $33( \pm 1.5)$ & $36( \pm 5.2)$ \\
\hline PUR B & $17( \pm 2.9)$ & $33( \pm 1.8)$ & $33( \pm 3.3)$ & $32( \pm 1.7)$ \\
\hline PUR C25 & $30( \pm 2.8)$ & $31( \pm 1.9)$ & $34( \pm 3.5)$ & $37( \pm 0.6)$ \\
\hline PUR C50 & $34( \pm 2.7)$ & $33( \pm 4.1)$ & $30( \pm 5.1)$ & $35( \pm 1.4)$ \\
\hline
\end{tabular}

${ }^{1}$ Result indicates no water droplet sliding at a tilting angle of $90^{\circ}$ (end of test).

The results for the four fresh (unaged) coatings of this study showed hydrophobic character, with WCA $>100^{\circ}$ and SFE $<23 \mathrm{mN} / \mathrm{m}$. The SFE slightly increased in the following order: PUR A < PUR B = PUR C25 < PUR C50. This correlated well with the degree of silanization, with the highest concentration for PUR A. After $200 \mathrm{~h}$ and $500 \mathrm{~h}$ of UV exposure, only minor changes for WCA and SFE were observed for all coatings. After a period of $1000 \mathrm{~h}$, significant changes were assessed, with WCA below the hydrophobic level $\left(<90^{\circ}\right)$ and SFE around $30 \mathrm{mN} / \mathrm{m}$. The different initial crosslinking densities and silanization degrees of the coating materials had no obvious effects on these surface parameters during UV-caused ageing.

Fresh coatings of PUR A and PUR B showed significantly lower initial WSA and CAH, compared to PUR C25 and PUR C50. This difference was not caused by the silane compound, as PUR B and PUR C25 were at comparable levels. The main difference between these coatings is the crosslinking density, which was increased in PUR C25 and even further in PUR C50. This may initially result in higher concentrations of oxygen atoms at the surfaces of PUR C25 and PUR C50, resulting in interactions with water molecules and higher WSA and CAH values.

After 200 h of UV ageing, all coatings had comparable levels, due to increased WSA and CAH values for PUR A and PUR B. Here, the moderate crosslinking density may have resulted in an initial degradation (including the loss of functional Si-atoms), bringing all coatings to comparable levels. Further UV ageing led to increased WSA at $>90^{\circ}$ (i.e., no 
water droplet sliding during duration of test) after $1000 \mathrm{~h}$ for PUR A, PUR B, and PUR C25. For PUR C50, WSA was still measurable, even if its standard deviations were high after UV treatment. The sensitivity of this parameter was the highest in this study, but was also linked to high data scattering, likely caused by the local inhomogeneity of the aged surfaces.

CAH remained comparably stable after its initial increase in PUR A and PUR B after $200 \mathrm{~h}$. Moderate increasing steps occurred over the remaining ageing period.

In general, SFE and WCA data for coatings in this test changed significantly after $1000 \mathrm{~h}$. These late effects were unexpected. In contrast, the sensitivity of WSA was the highest with significant changes after $200 \mathrm{~h}$ of UV exposure for PUR A and PUR B and after $500 \mathrm{~h}$ for PUR C25 and PUR C50. Further assessments related to the effects on the icephobic performances are part of this study.

\subsubsection{Roughness}

Surface roughness is considered another important parameter for assessing the icephobic performance of coatings, which also has a significant impact on the surface wettability. Increased surface roughness may result, on one hand, in improved wetting behavior, which can be used for surface pre-treatment to achieve good wetting and adhesion properties of coatings. On the other hand, specific hierarchical surface structures may result in superhydrophobic surfaces, which have been widely discussed for use as icephobic coatings [30-32]. However, the current study is focused on the use of smooth surfaces, as the durability and ice formation due to impacting (super cooled) water droplets are expected to be more beneficial for the considered application types. Figure 3 summarizes the $R_{a}$ and $R_{z}$ values derived from tactile Perthometer measurements for the fresh and aged coatings in this study.

The surface roughness of all fresh coatings in this study was low (with $R_{a}<0.2 \mu \mathrm{m}$ ), indicating very smooth coating surfaces. However, significantly higher values for $R_{a}$ and $\mathrm{R}_{\mathrm{z}}$ can be observed for PUR A and PUR B, compared to PUR C25 and PUR C50. The latter two were formulated to increase the crosslinking density, resulting in tougher (and smoother) surfaces. Additionally, only slight changes in surface roughness were observed for these two coatings during the UV ageing procedure. In contrast, for PUR A, significant changes were observed after $500 \mathrm{~h}$ of UV exposure, while for PUR B, an increasing trend of the roughness parameters was observed over the entire ageing period.

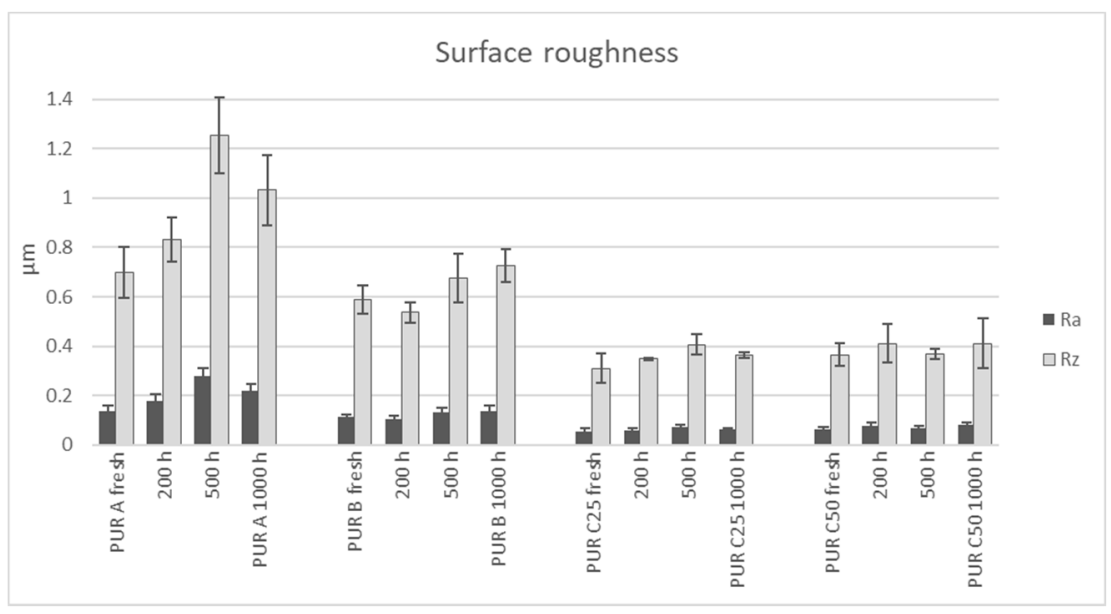

Figure 3. Roughness values $R_{a}$ and $R_{z}$ for fresh and $U V(B)$-aged coating surfaces (durations as indicated), representing the mean of 18 single measurements and the resulting standard deviations.

\subsubsection{Summary}

To summarize the surface property determinations, it can be stated that the coatings PUR A and PUR B (high silanization grades, moderate crosslinking densities) started with 
reduced wettability results for WSA and CAH compared to PUR C25 and PUR C50 (lower silanization grades, higher crosslinking densities). These parameters are assumed to be beneficial for the icephobic performance. Nevertheless, these assumed advantages of PUR A and PUR B were already lost after only $200 \mathrm{~h}$ of UV exposure, resulting in comparable wettability properties for all aged materials in this study. For the materials with higher crosslinking densities (PUR C25 < PUR C50), lower roughness values and only limited changes due to UV ageing were observed in comparison to PUR A and PUR B. Whether this had an impact on ice adhesion measurements is detailed in the following section.

\subsection{Change in Ice Adhesion Strength Due to UV(B)-Ageing}

The ice adhesion strength for the four coatings was assessed on both fresh and aged surfaces that had received UV ageing for $200 \mathrm{~h}, 500 \mathrm{~h}$, and $1000 \mathrm{~h}$. Testing of three specimens per coating material and threefold measurement was conducted, with means and standard deviations expressed in Figure 4.

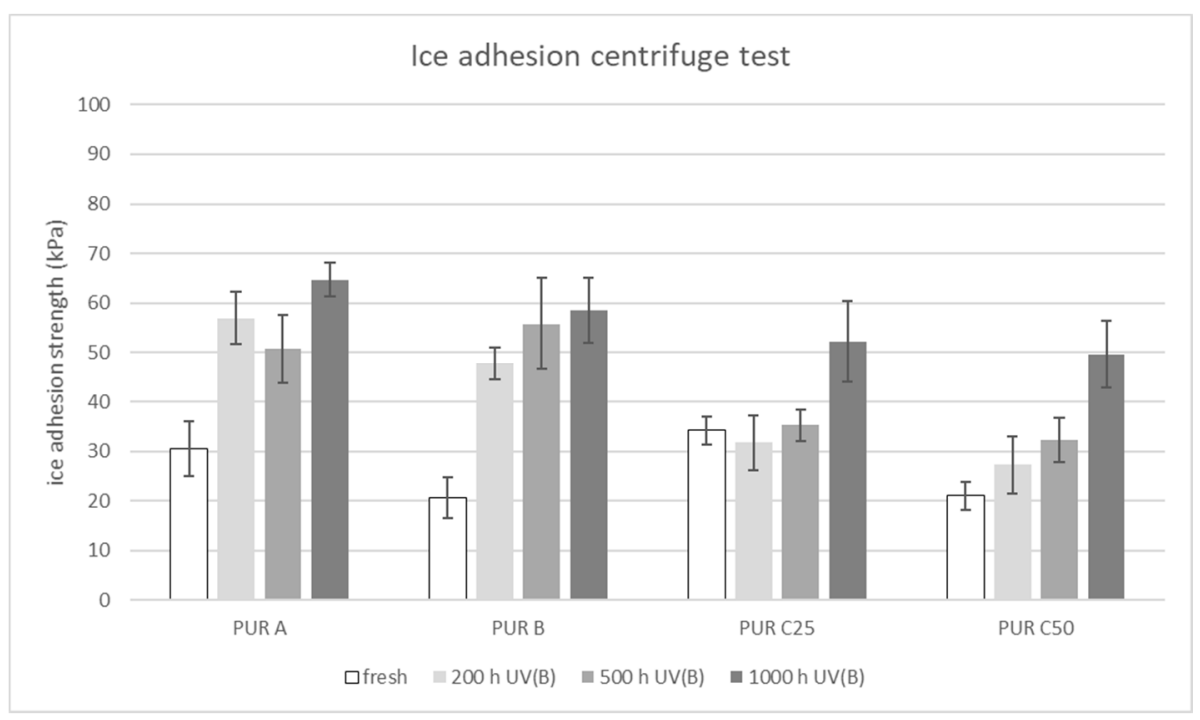

Figure 4. Results of ice adhesion centrifuge test $(\mathrm{kPa})$, representing the mean of nine single measurements and resulting standard deviations for coatings prior to and after UV(B)-ageing, as indicated.

The results of the IFAM ice adhesion centrifuge test gave comparatively low levels, with values from $20 \mathrm{kPa}$ to $35 \mathrm{kPa}$ ice adhesion strength for fresh coatings, which is in the range of "low ice adhesion" coatings [33] and close to the values necessary for the passive removal of ice from, for example, aircraft wings [13]. The three repeated icing/de-icing cycles indicated no increasing nor decreasing trends in ice adhesion strength.

For coatings PUR A and PUR B, a clear increase in the ice adhesion strength was obvious after $200 \mathrm{~h}$ of UV exposure, with further UV exposure leading to no further increase. For coatings PUR C25 and PUR C50, a significant increase in ice adhesion strength was observed after $1000 \mathrm{~h}$ of UV exposure, keeping in mind that the values are still at a low level (around $50 \mathrm{kPa}$ ).

The measurement data of ice adhesion tests depend on complex relationships between test conditions and design, which currently prevent the comparison of absolute data between different test facilities. In general, at Fraunhofer IFAM, the range of test results lies between $10 \mathrm{kPa}$ and $400 \mathrm{kPa}$. Below $10 \mathrm{kPa}$, the ice tends to fall off prior to the installation of the test specimen into the centrifuge. Above $400 \mathrm{kPa}$, the cohesive failure of ice dominates, which leads to ice residues on the surface after the test. This happens, for example, with uncoated aluminum or primer coatings. The tight range of test results for the coatings in this study was unexpected and may have interfered with the correlation assessments between surface properties and ice adhesion strength, which is assessed in the following section. 


\subsection{Correlation Assessments}

To pave the way for the use of icephobic coatings, an improved understanding of parameter correlations and performance durability are necessary. In this study, we focus on the identification of relevant parameter correlations, at least for the class of silanized PUR coatings, a promising material class for future applications. Figures 5-8 in the following sub-sections show the findings for each coating separately, expressing the percentage change in surface properties and ice adhesion strength compared to the fresh (unaged) coating surfaces.

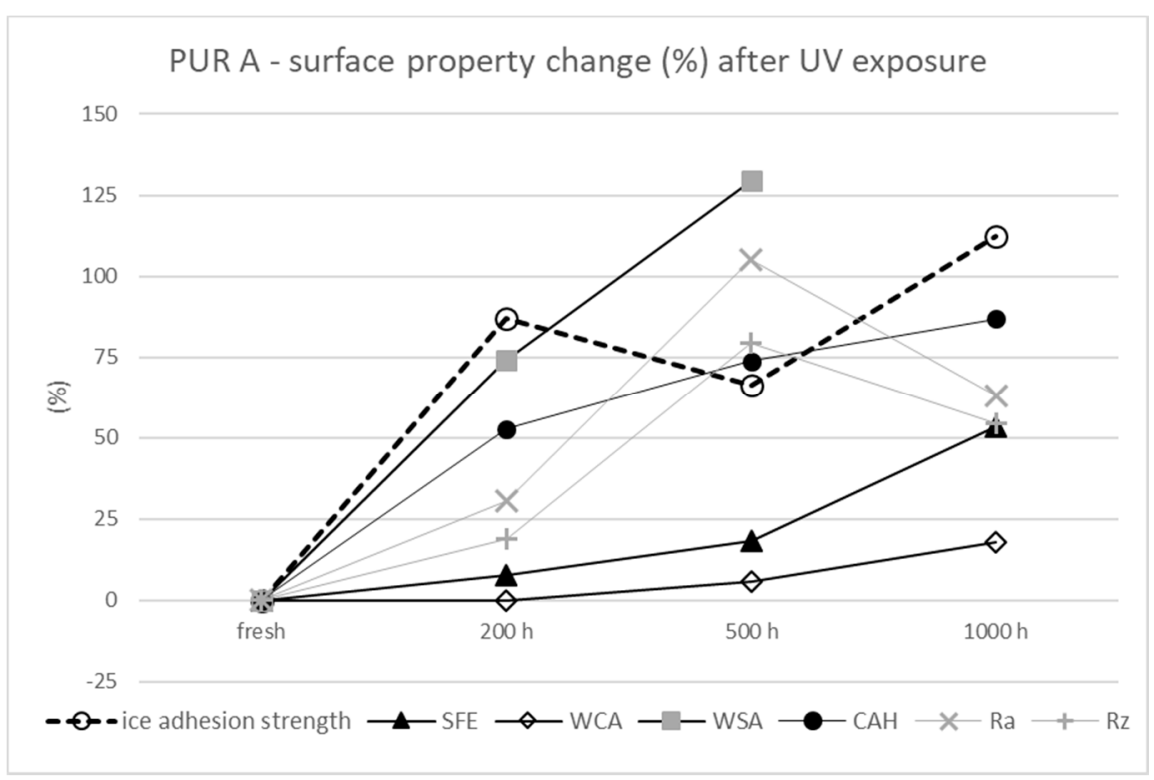

Figure 5. Change in surface properties and ice adhesion strength (\%) due to UV(B)-ageing of the coating "PUR A" (maximum value of $y$-axis 150\%).

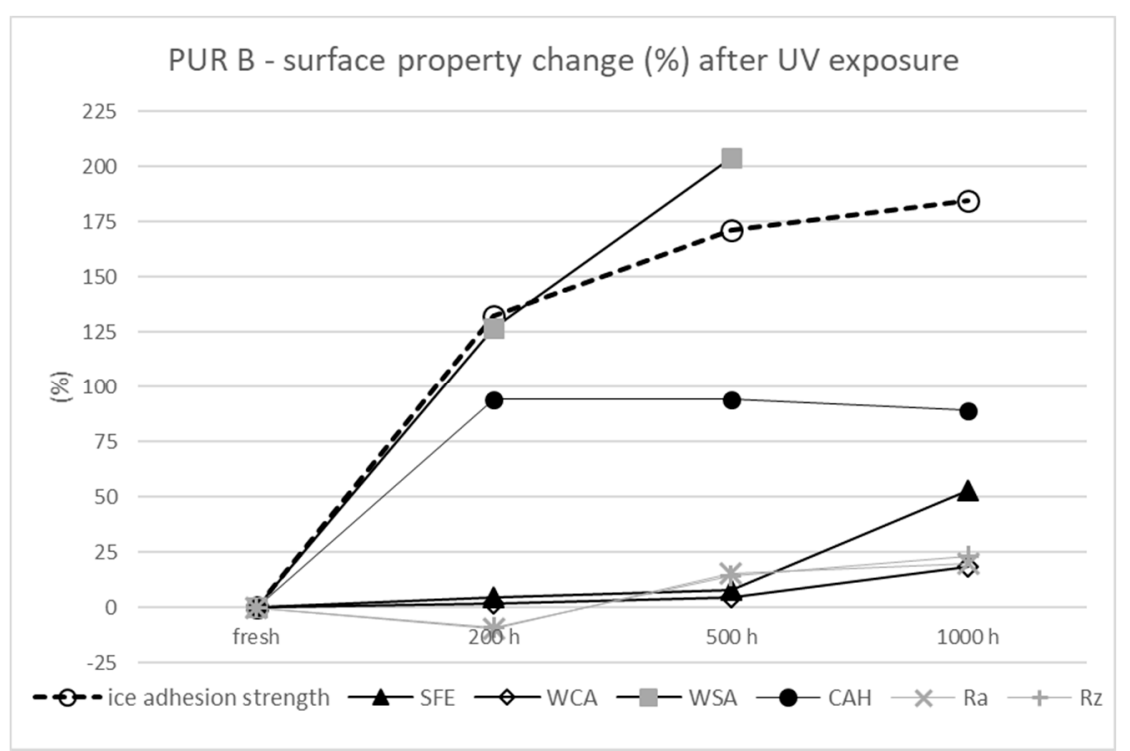

Figure 6. Change in surface properties and ice adhesion strength (\%) due to UV(B)-ageing of the coating "PUR B" (maximum value of $y$-axis 225\%). 


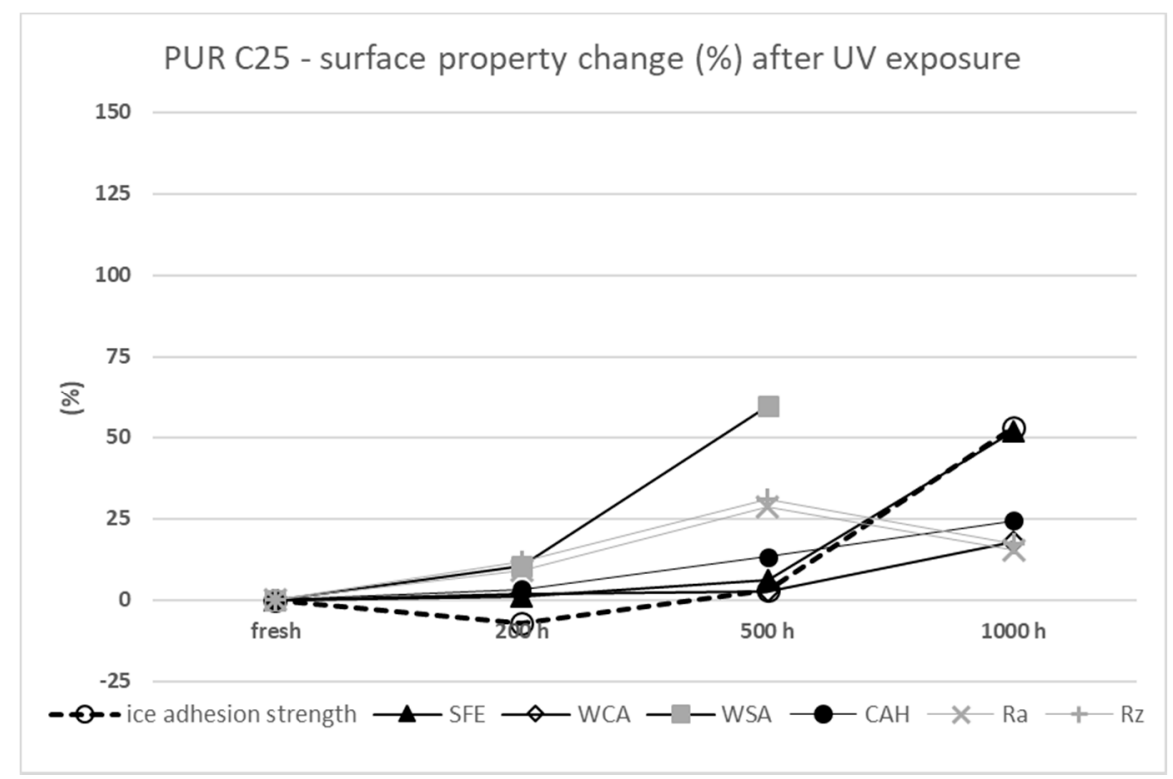

Figure 7. Change in surface properties and ice adhesion strength (\%) due to UV(B)-ageing of the coating "PUR C25" (maximum value of $y$-axis 150\%).

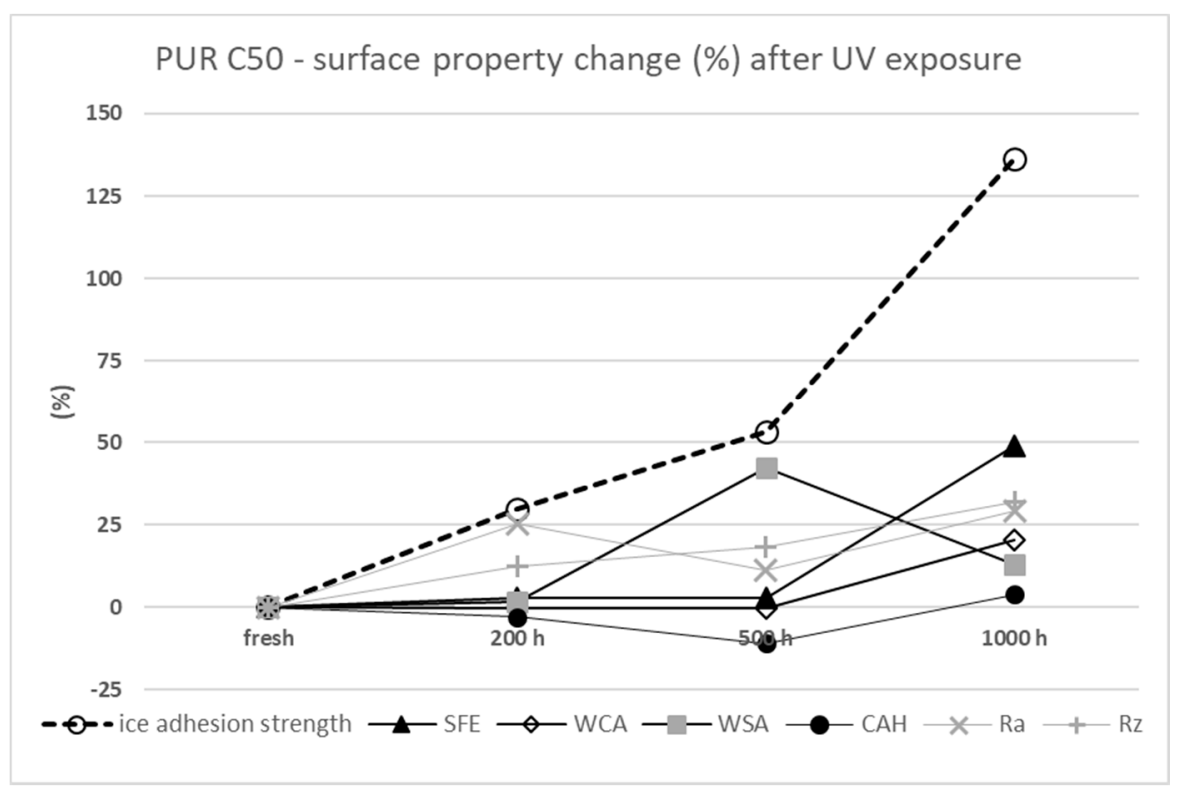

Figure 8. Change in surface properties and ice adhesion strength (\%) due to UV(B)-ageing of the coating "PUR C50" (maximum value of $y$-axis 150\%).

\subsubsection{Coating "PUR A"}

"PUR A" was the coating with the highest silane content in this study, along with moderate crosslinking density. Parameter changes over the period of $1000 \mathrm{~h}$ of $\mathrm{UV}(\mathrm{B})$ exposure are expressed in Figure 5.

The percentage change of the ice adhesion strength (dotted line in all graphs) was $>75 \%$ after $200 \mathrm{~h}$ of UV ageing for PUR A. WSA, with the highest sensitivity in this study, seemed to indicate this performance change best, followed by CAH. The parameters WCA, $\mathrm{SFE}, \mathrm{R}_{\mathrm{a}}$, and $\mathrm{R}_{\mathrm{z}}$ were not correlated with the percentage change of the ice adhesion strength after $200 \mathrm{~h}$.

There was no further significant change in ice adhesion strength after $500 \mathrm{~h}$ and $1000 \mathrm{~h}$ of UV ageing (compare, also, with Figure 4); this finding is best represented by the CAH. In contrast, the WSA further increased after $500 \mathrm{~h}$ of UV ageing, which may have resulted 
in an overestimation of the ice adhesion strength. Additionally, the WSA was limited by the qualitative result of "no sliding angle detectable" $\left(>90^{\circ}\right)$ after $1000 \mathrm{~h}$ of UV ageing (not displayed in Figure 5), thus not further correlating with ice adhesion strength data. Changes in roughness data for PUR A were recorded, but did not correlate with the UV exposure time-dependent changes in the ice adhesion strength.

\subsubsection{Coating "PUR B"}

The "PUR B" coating had moderate silane content and similar moderate crosslinking density as "PUR A". Parameter changes over the period of $1000 \mathrm{~h}$ of UV(B) exposure are expressed in Figure 6.

The percentage change in the ice adhesion strength after $200 \mathrm{~h}$ of UV ageing was $>125 \%$ for PUR B. Again, the WSA indicated the performance change best, but indicates overestimation of the further increase in the ice adhesion strength beyond $200 \mathrm{~h}$ of UV exposure. There was no further significant change in ice adhesion strength after $500 \mathrm{~h}$ and $1000 \mathrm{~h}$ of UV ageing (compare, also, with Figure 4); the CAH correlates well with this finding. The parameters WCA, SFE, $\mathrm{R}_{\mathrm{a}}$, and $\mathrm{R}_{\mathrm{z}}$ were not correlated with the percentage change of the ice adhesion strength for PUR $B$.

\subsubsection{Coating "PUR C25"}

The "PUR C25" coating had moderate silane content and increased crosslinking density compared to "PUR A" and "PUR B". Parameter changes over the period of $1000 \mathrm{~h}$ of UV(B) exposure are expressed in Figure 7.

No significant changes were observed after $200 \mathrm{~h}$ of UV ageing for PUR C25. The ice adhesion strength only increased by $50 \%$ after $1000 \mathrm{~h}$ of UV ageing. This correlated best with the data for SFE. CAH and WCA also followed this trend but were less significant. The parameters WSA, $R_{a}$, and $R_{z}$ were not correlated with the development of the ice adhesion strength values.

\subsubsection{Coating "PUR C50"}

The "PUR C50" coating had the lowest silane content and the highest crosslinking density in this study. Parameter changes over the period of $1000 \mathrm{~h}$ of UV(B) exposure are expressed in Figure 8.

The percentage change of the ice adhesion strength for PUR C50 increased gradually, with the maximum change of $>125 \%$ after $1000 \mathrm{~h}$ of UV exposure. None of the assessed surface properties correlated well with this finding. The SFE increased significantly after $1000 \mathrm{~h}$ of UV exposure but, prior to this, no changes were observed for this surface property. These findings are, amongst others, further discussed in the following section.

\section{Discussion}

This study was aimed at the identification of correlations between surface properties and the ice adhesion strength for silanized PUR coatings throughout a standardized UVageing procedure. Additionally, the findings regarding the durability of icephobic effects, coating degradation processes, and potential monitoring tools are important prerequisites for the use of icephobic coatings in technical applications. It can be summarized that for the coatings PUR A (highest silanization and moderate crosslinking density) and PUR B (moderate silanization and moderate crosslinking density), initial degradation was already observed after only $200 \mathrm{~h}$ of UV ageing. Over the complete ageing period $(1000 \mathrm{~h})$, the ice adhesion strength and CAH were identified to be the best correlated parameters for these two coatings. For the coatings PUR C25 (moderate silanization and increased crosslinking density) and PUR C50 (lowest silanization and highest crosslinking density), the degradation behavior differed from the previous two and significant changes in surface properties and ice adhesion strength were observed after $1000 \mathrm{~h}$ of UV ageing. The SFE correlated best with the changes in ice adhesion strength. 
In summary, the results of this study demonstrate that coating-specific correlation parameters need to be identified. This agrees well with the findings of Niemelä-Anttonen et al., who conducted a study by grouping material classes (e.g., metals, bulk polymers, paints, and so on) and compared their ability to reduce ice adhesion strength by using a centrifuge test. They concluded that, due to the characteristic properties of each material, the general comparison beyond the different material groups might be challenging [34].

Research on correlating surface parameters has been widely conducted by many researchers (see, e.g., [35-38]). On one hand, material developers would benefit, as they obtain information about the surface properties that they should focus on. On the other hand, effective durability could be easily predicted and monitored during ageing processes in both lab-scale and technical environments. The results of these research activities are manifold, and sometimes contradictory, indicating the high complexity of the underlying processes and the incomparability of surfaces of different chemical and physical natures. Zou et al. concluded that, for surfaces in general, a higher water contact angle is not necessarily good for the reduction in the ice adhesion if the surface roughness is high [39]. Roughness effects have also been discussed by additional authors (e.g., $[35,36])$ and there is a basic understanding that increased surface roughness can be detrimental to the icephobic performance, especially for ice formations related to condensation and impacting supercooled water droplets. However, in this study, the roughness parameters $R_{a}$ and $\mathrm{R}_{\mathrm{z}}$ showed no correlation to the icephobic performance. It can be concluded that the conducted tactile Perthometer measurements are not sufficient as a monitoring tool for these smooth coating surfaces and, thus, more complex and sensitive techniques (e.g., 3D laser confocal microscopy, scanning electron microscopy) are necessary for the assessment of roughness dependences.

The reasons behind the differences in degradation performance for the four coatings considered in this study, which belong to one coating family, are complex. The first variable is the silane concentration, which can be reproduced by the SFE of fresh surfaces. However, this had no measurable effect on the ice adhesion strength. Crosslinking density is the second main variable of the coatings, which lead to differences in their degradation behaviors. This formulation parameter is decisive for the development of durable icephobic silanized PUR coatings and requires further attention in follow-up studies, which will include analytical surface assessments regarding chemical surface composition and mechanical strength during ageing processes. Additionally, the dependence of material properties (e.g., coating thickness, elastomeric behavior) on the icephobic performance as well as interfacial processes (e.g., water penetration, droplet impacts) should be addressed in follow-up studies. Finally, the validity of the ice adhesion measurement data needs to be proven. This will be realized, e.g., by conducting ice wind-tunnel tests with hybrid ice protection systems, in order to assess the actual performance under relevant icing conditions.

\section{Conclusions}

The results of this study demonstrate the significant progress in the development of durable icephobic coatings in the class of silanized PUR coatings. However, the development of general rules to predict and monitor icephobic performances is unlikely, due to the different degradation processes present even within one material class. As a result, promising coating candidates with proven durability under technically relevant ageing regimes should be put through an extensive evaluation process in order to identify their degradation mechanisms and relevant correlating parameters for monitoring purposes. The definition of a quantifiable level of degradation may help to indicate the loss of performance during operations and to support the definition of technical requirements. After this study, the challenges related to the integration of icephobic coatings into technical ice protection schemes remain. Our next steps to improve the understanding of the needs for ice-testing are to conduct tests with well-characterized materials in combination with heating systems under ice wind-tunnel conditions. 
Author Contributions: Conceptualization, C.S. and N.R.; methodology, B.S. and N.R.; validation, C.S., B.S., and N.R.; formal analysis, N.R.; investigation, B.S.; resources, C.S.; writing-original draft preparation, N.R.; writing—review and editing, V.S.; visualization, N.R.; supervision, V.S.; project administration, N.R.; funding acquisition, V.S. All authors have read and agreed to the published version of the manuscript.

Funding: This research was funded by Fraunhofer IFAM, Germany, and Airbus Operations GmbH, Germany.

Institutional Review Board Statement: Not applicable.

Informed Consent Statement: Not applicable.

Data Availability Statement: Not applicable.

Acknowledgments: The authors would like to thank colleagues at Fraunhofer IFAM working in the field of coating technologies and ice-related topics for their efforts in supporting this study. Airbus Operations $\mathrm{GmbH}$ and Fraunhofer IFAM are thanked for the financial support of this work.

Conflicts of Interest: The authors declare no conflict of interest.

\section{References}

1. Wohl, C.J.; Berry, D.H. Contamination Mitigating Polymeric Coatings for Extreme Environments; Wohl, C.J., Berry, D.H., Eds.; Part II: Ice Contamination-Mitigating Coatings; Advances in Polymer Science 284; Springer Nature: Cham, Switzerland, 2019; pp. 52-214. [CrossRef]

2. Rehfeld, N.; Berton, B.; Diaz, F.; Tanaka, T.; Morita, K.; Kimura, S. JediAce: Japanese-European De-Icing Aircraft Collaborative Exploration. In Aviation in Europe - Innovating for Growth, Proceedings of the Seventh European Aeronautics Days, London, UK, 20-22 October 2015; Publications Office of the European Union: Luxembourg, 2017; ISBN 978-92-79-59141-9. [CrossRef]

3. Esmeryan, K.D. From Extremely Water-Repellent Coatings to Passive Icing Protection-Principles, Limitations and Innovative Application Aspects. Coatings 2020, 10, 66. [CrossRef]

4. Kreder, M.J.; Alvarenga, J.; Kim, P.; Aizenberg, J. Design of Anti-Icing Surfaces: Smooth, Textured or Slippery? Nat. Rev. Mater. 2016, 1, 1-15. [CrossRef]

5. Parent, O.; Ilinca, A. Anti-icing and De-icing Techniques for Wind Turbines: Creitical Review. Cold Reg. Sci. Technol. 2021, 65, 88-96. [CrossRef]

6. Koivuluoto, H.; Hartikainen, E.; Niemelä-Anttonen, H. Termally Sprayed Coatings: Novel Surface Engineering Strategy towards Icephobic Solutions. Materials 2020, 13, 1434. [CrossRef] [PubMed]

7. Antonini, C.; Innocenti, M.; Horn, T.; Marengo, M.; Amirfazli, A. Understanding the Effect of Superhydrophobic Coatings on Energy Reduction in Anti-Icing Systems. Cold Reg. Sci. Technol. 2011, 67, 58-67. [CrossRef]

8. Morita, K.; Kimura, S.; Sakaue, H. Hybrid System Combining Ice-Phobic Coating and Electrothermal Heating for Wing Ice Protection. Aerospace 2020, 7, 102. [CrossRef]

9. Huang, X.; Tepylo, N.; Pommier-Budinger, V.; Budinger, M.; Bonaccurso, E.; Villedieu, P.; Bennani, L. A Survey of Icephobic Coatings and their Potential Use in a Hybrid Coating/Active Ice Protection System for Aerospace Applications. Prog. Aerosp. Sci. 2019, 105, 74-97. [CrossRef]

10. Yeong, H.Y.; Milionis, A.; Loth, E.; Sokhey, J. Self-lubrificating Icephobic Elastomer Coating (SLIC) for Ultralow Ice Adhesion with Enhanced Durability. Cold Reg. Sci. Technol. 2018, 148, 29-37. [CrossRef]

11. Tetteh, E.; Loth, E. Reducing Static and Impact Ice Adhesion with a Self-Lubricating Icephobic Coating (SLIC). Coatings 2020, 10, 262. [CrossRef]

12. Soltis, J.; Palacios, J.; Eden, T.; Wolfe, D. Evaluation of Ice-Adhesion Strength on Erosion-Resistant Materials. AIAA J. 2015, 53, 1825-1835. [CrossRef]

13. Golovin, K.; Kobaku, S.P.R.; Lee, D.H.; Di Loreto, E.T.; Mabry, J.M.; Tuteja, A. Designing Durable Icephobic Surfaces. Sci. Adv. 2016, 2. [CrossRef] [PubMed]

14. Rehfeld, N.; Speckmann, B.; Grünke, S. Durability of Icephobic Materials. In Proceedings of the IWAIS 2019, Reykjavik, Iceland, 23-27 June 2019.

15. Schulz, M.; Sinapius, M. Evaluation of Different Ice Adhesion Tests for Mechanical Deicing Systems. SAE Tech. Pap. 2015. [CrossRef]

16. Work, A.; Lian, Y. A Critical Review of the Measurement of Ice Adhesion to Solid Substrates. Prog. Aerosp. Sci. 2018, 98, 1-26. [CrossRef]

17. Rehfeld, N.; Berton, B.; Morita, K.; Kimura, S. A Way Forward to Design Efficient Wing Ice Protection Systems. In Proceedings of the Greener Aviation Conference, Brussels, Belgium, 11-13 October 2016. GA2016_135.

18. Kool, N.; Chevrette, G.; Orchard, D.M. Testing of Elastomer Icephobic Coatings. In Proceedings of the Conference Paper for 2018 Atmospheric and Space Environment Conference, Atlanta, Georgia, 25-29 June 2018. [CrossRef] 
19. Rønneberg, S.; Zhuo, Y.; Laforte, C.; He, J.; Zhang, Z. Interlaboratory Study of Ice Adhesion Using Different Techniques. Coatings 2019, 9, 678. [CrossRef]

20. Berry, H.B.; Wohl, C.J. Aerospace and Marine Environments as Design Spaces for Contamination-Mitigation Polymeric Coatings. In Contamination Mitigating Polymeric Coatings for Extreme Environments; Wohl, C.J., Berry, D.H., Eds.; Springer International Publishing AG: Cham, Switzerland, 2019; pp. 1-16. [CrossRef]

21. De Pauw, D.; Dolatabadi, A. Effect of Superhydrophobic Coating on the Anti-Icing and De-Icing of an Airfoil. AIAA J. Aircr. 2017, 54, 490-499. [CrossRef]

22. Janjua, Z.A.; Turnbull, B.; Choy, K.-L.; Pandis, C.; Liu, J.; Hou, X.; Choia, K.-S. Performance and Durability Tests of Smart Icephobic Coatings to Reduce Ice Adhesion. Appl. Surf. Sci. 2017, 407, 555-564. [CrossRef]

23. Liu, G.; Yuan, Y.; Liao, R.; Wang, L.; Gao, X. Fabrication of Porous Slippery Icephobic Surface and Effect of Lubricant Viscosity on Anti-icing Properties and Durability. Coatings 2020, 10, 896. [CrossRef]

24. DIN EN ISO 2808:2019; Beschichtungsstoffe—Bestimmung der Schichtdicke; Beuth Verlag GmbH: Berlin, Germany, 2019.

25. DIN EN ISO 16474-3; Beschichtungsstoffe-Künstliches Bestrahlen oder Bewittern in Geräten—Teil 3: UV-Leuchtstofflampen; Beuth Verlag GmbH: Berlin, Germany, 2021.

26. DIN EN ISO 19403-2,-7: Beschichtungsstoffe—Benetzbarkeit-Teil 2: Bestimmung der freien Oberflächenenergie fester Oberflächen durch Messung des Kontaktwinkels, Teil 7: Messung des Kontaktwinkels bei Neigetischexperimenten (Abrollwinkel); Beuth Verlag GmbH: Berlin, Germany, 2020.

27. Brassard, J.D.; Laforte, C.; Guerin, F.; Blackburn, C. Icephobicity: Definition and Measurement Regarding Atmospheric Icing. In Contamination Mitigating Polymeric Coatings for Extreme Environments; Wohl, C.J., Berry, D.H., Eds.; Springer International Publishing AG: Cham, Switzerland, 2019; pp. 123-144. [CrossRef]

28. Orchard, D.; Clark, C.; Chevrette, G. Reducing Aviation Icing Risk: Ice Adhesion Measurement in the NRC's Altitude Icing Wind Tunnel. In Proceedings of the SAE AeroTech Conference, Fort Worth, TX, USA, 26-28 September 2017.

29. Laforte, C.; Beisswenger, A. Icephobic Material Centrifuge Adhesion Test. In Proceedings of the IWAIS 2005, Montréal, QC, Canada, 12-16 June 2005.

30. Kulinich, S.A.; Farhadi, S.; Nose, K.; Du, X.W. Superhydrophobic Surfaces: Are They Really Ice-Repellent? Langmuir 2011, 27, 25-29. [CrossRef]

31. Khedir, K.R.; Kannarpady, G.K.; Ryerson, C.; Biris, A.S. An Outlook on Tunable Superhydrophobic Nanostructural Surfaces and their Possible Impact on Ice Mitigation. Prog. Org. Coat. 2017, 112, 304-318. [CrossRef]

32. Asadollahi, S.; Farzaneh, M.; Stafford, L. On the Icephobic Performance of Organosilicon-based Surface Structures Developed through Atmospheric Pressure Plasma Deposition in Nitrogen Plasma. Coatings 2019, 9, 679. [CrossRef]

33. Hejazi, V.; Sobolev, K.; Nosonovsky, M. From Superhydrophobicity to Icephobicity: Forces and Interaction Analysis. Sci. Rep. 2013, 3. [CrossRef] [PubMed]

34. Niemelä-Anttonen, H.; Kiilakoski, J.; Vuoristo, P.; Koivuluoto, H. Icephobic Performance of Different Surface Designs and Materials. In Proceedings of the IWAIS 2019, Reykjavik, Iceland, 23-27 June 2019.

35. Yin, L.; Xia, Q.; Xue, J.; Yang, S.; Wang, Q.; Chen, Q. In situ Investigation of Ice Formation on Surfaces with Representative Wettability. Appl. Surf. Sci. 2010, 256, 6764-6769. [CrossRef]

36. Kulinich, S.A.; Farzaneh, M. On Ice-Releasing Properties of Rough Hydrophobic Coatings. Cold Reg. Sci. Technol. 2011, 65, 60-64. [CrossRef]

37. Meuler, A.J.; Smith, J.D.; Varanasi, K.K.; Mabry, J.M.; McKinley, G.H.; Cohen, R.E. Relationships between Water Wettability and Ice Adhesion. ACS Appl. Mater. Interfaces 2010, 2, 3100-3110. [CrossRef]

38. Hyugaji, T.; Kimura, S.; Endo, H.; Hasegawa, M.; Sakaue, H.; Morita, K.; Yamagishi, Y.; Rehfeld, N.; Berton, B.; Diaz, F.; et al. Runback Water Behavior on Hydro-phobic/philic Surfaces of Circular Cylinder Placed in Flow Field. SAE Tech. Pap. 2015. [CrossRef]

39. Zou, M.; Beckford, S.; Wei, R.; Ellis, C.; Hatton, G.; Miller, M.A. Effects of Surface Roughness and Energy on Ice Adhesion Strength. Appl. Surf. Sci. 2011, 257, 3786-3792. [CrossRef] 